\title{
Commonplace
}

\section{Journal Prompts}

Frankie Mastrangelo

Published on: Aug 10, 2020

DOI: $10.21428 / 6 \mathrm{ffd} 8432.79$ eea7d1

License: Creative Commons Attribution 4.0 International License(CC-BY 4.0). 


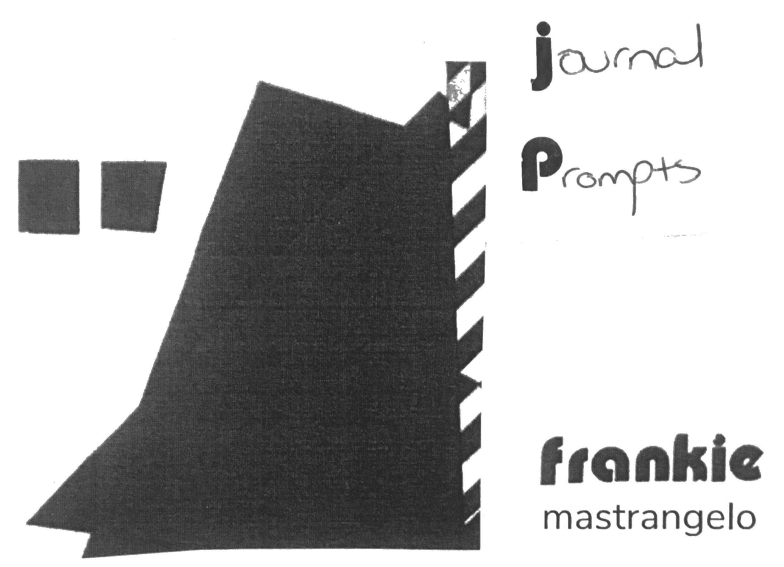

\section{Introduction 1}

These journal prompts were used in my Intro to Gender, Sexuality, and Women's Studies and Advanced Writing classes during the period of April through July 2020. Journals emerged as a way to connect with students as people and check in during COVID times, considering it's difficult to know where each student is at when we can't interact in person. Students' shifting work, family, and newfound virtual student responsibilities facilitate more opportunities for overwhelm and disconnection, so I'm thinking a lot about what it looks like to build and maintain class communities in our weird reality. Since the topics I teach engage the personal and the political as a framework for understanding structural power, the prompts made use of personal narrative to gain a more grounded, resonant understanding of course content. I make journals a low-stakes, "A for completion" assignment to allow students to create a (digital or physical) space of their own for processing experience and emotion outside the confines of rigid academic evaluation (COVID times have inspired lots of reflection for me on the colonial imposition of traditional grading structures, and how conceptions of rigor can limit the prioritization of compassion -- but I can bore y'all with those thoughts at another time :) Anyhow, I hope folks find these prompts useful, and feel free to get in touch with me by email if you'd like to talk about them more. $\underline{2}$ 
Commonplace

Journal Prompts

magine were living in a world where people's basic needs like housing, food, and healthcare are taken care of. in this world, police + prisons have been phased at of existence, as alternative forms of crisis intervention and accountability are now the norm.

ow would you plans, dreams, and ways of being in the world shift if these changes took effect?

Think back on how you engaged with social media yesterday. Consider what social media you may have checked, what conversations you saw happening/ participated in, what thoughts/feelings that engagement inspired for you.

What do these reflections tell you about your social media habits? o you enchanter different digital experiences thru work connections, family, friends?

low do structures of power racism, cissexism, sexism etc.) make themselves felt in yard digital life?

3 
Commonplace

Journal Prompts

What is home? The place I was born? Where I grew up? Where I locate my community. my people? Who are "m ypeople"? Is home a geographical space, a historical space, an emotional, sensory space?

- Chandra Tarpade

Mohanty

What feels like home to you? if home is difficult to define, attempt to describe why.

Mnansa Benbow and Rosin Lippi -Green discs how the standardization of language/written expression mandates a lack \& variation in order to conform to rules + conventions. "proper" grammar, margmavizing accents, depersonalizing writing -. it's all rooted in upholding thestandares of a white supremacist, colonial linguistic system.

What do you think your $k-12$ experience would have looked like if you didn't need to conform to the standards + conventions of language + written expression? 

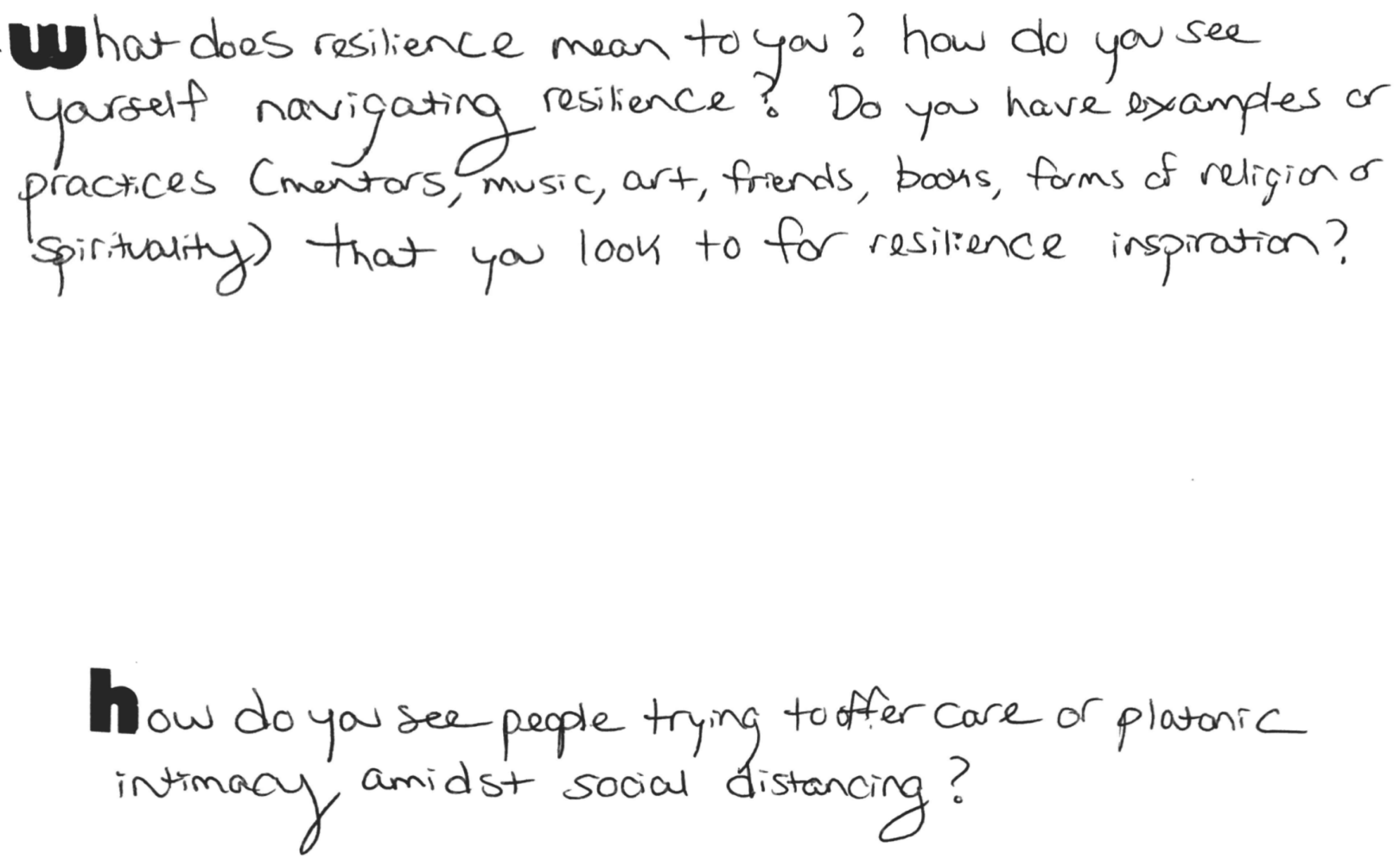

\section{Transcript of the Prompts}

Prompt 1: Imagine we're living in a world where people's basic needs like housing, food, and healthcare are taken care of. In this world, police and prisons have been phased out of existence, as alternative forms of crisis intervention and accountability are now the norm. How would your plans, dreams, and ways of being in the world shift if these changes took effect?

Prompt 2: Think back on how you engaged with social media yesterday. Consider what social media you may have checked, how you engaged with it, what conversations you saw happening or 
participated in, what thoughts or feelings that engagement inspired for you. What do these reflections tell you about your social media habits? Do you encounter different digital experiences through work connections, family, friends? How do structures of power (racism, cissexism, sexism, etc.) make themselves felt in your digital life?

Prompt 3: "What is home? The place I was born? Where I grew up? Where I locate my community, my people? Who are 'my people'? Is home a geographical space, a historical space, an emotional, sensory space?" - Chandra Talpade Mohanty - What feels like home to you? If home is difficult to define, attempt to describe why.

Prompt 4: Anansa Benbow and Rosina Lippi-Green discuss how the standardization of language \& written expression mandates a lack of variation in order to conform to rules and conventions. "Proper" grammar, marginalizing accents, depersonalizing writing -- it's all rooted in upholding the standards of a white-supremacist, colonial linguistic system. What do you think your K-12 experience would have looked like if you didn't need to conform to the standards and conventions of language \& written expression?

Prompt 5: What does resilience mean to you? How do you see yourself navigating resilience? Do you have examples or practices (mentors, music, art, friends, books or guides, forms of religion or spirituality) that you look to for resilience inspiration?

Prompt 6: How do you see people trying to offer care or platonic intimacy amidst social distancing?

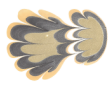

\section{Footnotes}

1. *A big thank you to interdisciplinary scholar Alexis Lothian for pedagogical inspiration on "prompt 2" related to social media habits - check out her site QueerGeekTheory.org for great syllabi and activities that engage queer and feminist studies in understandings of mediated cultures. $\boxminus$

2. frankie.mastrangelo@gmail.com $\underline{\underline{\text { frang }}}$ 